\title{
Nômades digitais: em busca de comunidades, do almanaque às redes sociais
}

\author{
Digital nomads: in search of communities, from the \\ almanac to social media
}

Luciana dos Santos Salles

Universidade Federal do Rio de Janeiro - UFRJ

Marlon Augusto Barbosa

Universidade Federal do Rio de Janeiro - UFRJ

\section{DoI}

https://doi.org/10.37508/rcl.2021.n46a464

\section{RESUMO}

O presente texto pretende apresentar e analisar uma certa peregrinação da forma e do conteúdo do almanaque que, historicamente, assume, com o tempo, novos recortes temáticos, preservando de sua tradição antiga quase que apenas o caráter enciclopédico, informativo, e a perspectiva temporal de publicação sazonal, como anuário. O objetivo é demonstrar que o almanaque funciona como um veículo de congregação de coletividades e, por isso mesmo, construtor de uma comunidade -, de geração algorítmica de bolhas e padrões de vivência e consumo. Com diferentes experiências, sistemas de comunicação como o Facebook, o Twitter ou o Instagram parecem configurar a versão tecnológica correspondente ao manakh de nossos dias. Cada uma dessas redes funciona como o espaço em que nos reunimos em torno de experiências individuais e informações em torno de temas e interesses cada vez mais específicos. São lugares de discurso e linguagem que propiciam a construção de diálogos, 
encontros, comunidades inteiras formadas por sujeitos de um infinito nomadismo que caminham sem descanso em busca de possibilidades de conhecimento e comunhão.

Palavras-chave: Almanaque, redes sociais, comunicação, comunidades digitais, homo digitalis.

\section{Abstract}

This text intends to present and analyze a certain pilgrimage of the form and content of the almanac that, historically, takes on new thematic outlines over time, preserving from its ancient traditions almost only the encyclopedic, informative character and the temporal perspective of seasonal publication timeline, such as the yearbook. The objective is to demonstrate that the almanac works as a vehicle for bringing together communities and, for that very reason, as a builder of a community for the algorithmic generation of bubbles and patterns of living and consumption. With different experiences, communication systems like Facebook, Twitter or Instagram seem to configure the technological version corresponding to the manakh of our days. Each of these networks works as a space where we gather around individual experiences and information around increasingly specific themes and interests. They are places of discourse and language that enable the construction of dialogues, meetings, entire communities formed by subjects of an infinite nomadism who walk restlessly in search of possibilities of knowledge and communion.

KEYWORDS: Almanac, social networks, communication, digital communities, homo digitalis.
Ó menina vai ver nesse almanaque
como é que isso tudo começou
Diz quem é que marcava o tic-tac
e a ampulheta do tempo disparou
Chico Buarque

Curtindo a dica de Chico, vou em busca do começo; ver, em diversos textos, como tudo começou. Mas é difícil mapear um início tão distante: há notícias e vestígios do almanaque desde o século XIII 
a.C., entre as areias do Egito. Quem marcava o tic-tac antes da ampulheta do tempo disparar era, de fato, um relojoeiro de nome $A b u$ Ixaque Ibraim al-Zarcali, chamado de Arzaquel pelos falantes do Latim e suas variações. Matemático, astrólogo e mestre da astronomia islâmica, teria sido o responsável pela chegada do almanaque ao ocidente, como formato de registro e divulgação da linguagem dos astros entre mouros e brancos em diálogo no reino de Leão e Castela.

Segundo os historiadores ocidentais, os almanaques chegam à Europa no final da Idade Média, com o aumento do interesse pelas ciências e números vindos do oriente, junto aos temperos e especiarias. Sabor e saber - para jogar com a etimologia da palavra tão bem recuperada por Roland Barthes em sua Aula - trazem a um novo lado do mundo um formato antigo, anterior à imprensa de tipos móveis criada por Gutenberg.

Logo o tema astronomia-astrologia vai sendo ampliado. Sem deixar de lado os astros, o almanaque vai ganhando contornos de calendário, marcando efemérides e eventos entre o céu e a terra, e aos poucos o formato vai se desdobrando em novos recortes temáticos, preservando de sua tradição antiga quase que apenas o caráter enciclopédico, informativo, e a perspectiva temporal de publicação sazonal, como anuário. Expondo aquilo a que historicamente estão sujeitas todas as formas: a desdobramentos sucessivos, metamorfoses e transformações não apenas de suas estruturas, mas também de suas funções. Fadados à repetição, todos os textos, todas as formas, de alguma maneira, são gerados a partir de outros textos e de outras formas. Objetos maleáveis, textos e formas nascem de pedaços de outros textos e de outras formas e são aprisionados num jogo contínuo de repetições e desdobramentos: um caminhar constante de totalidade para fragmento e de fragmento para totalidade, sem nunca se alcançar um lugar estável. Trata-se sempre de um avanço nômade das formas: fragmentos de mundo arrancados de um lugar próprio e lançados numa esteira de múltiplas associações e transformações. 
Ainda hoje os almanaques - mais ou menos conscientes de sua história enquanto gênero - são fartamente consumidos. Mas ao contrário dos mais tradicionais, hoje temos imensa diversidade nesse tipo de publicação, voltados para públicos-alvo muito variados trazendo à tona um verdadeiro exercício de pluralidade, mostrando, sobretudo, as diferentes comunidades de leitores que existem. No mercado editorial de nosso século, almanaques podem ser coletâneas de histórias em quadrinhos, podem ser reuniões de receitas culinárias, podem ser compilados de informações turísticas... Antes de serem substituídas pelas versões digitais, as maiores enciclopédias em papel recorriam aos almanaques como forma de se manterem atualizadas - caso exemplar eram os volumes anuais publicados pela Enciclopédia britânica, chamados de "Livro do Ano" e "Ciência e Futuro", com suas matérias, novos verbetes e até mesmo obituários. $\mathrm{O}$ recordista do gênero em reconhecimento mundial, mesmo entre não leitores, é justamente o que registra recordes alheios: o Guinness Book é, antes de tudo, um almanaque.

Se reconstituir - ao modo de um arqueológo - uma história tão antiga é empreitada complexa, difícil e que muitas vezes beira a ficção, a aposta em uma reconstituição pela etimologia não nos dá um caminho mais simples. A imprecisão na origem do termo se abre em uma tríade de hipóteses. 1. De al-manaj, recebemos a pista para a periodicidade anual, já que este é o nome árabe do círculo dos meses no relógio de sol. 2. Al-manah também aponta para uma leitura espaço-temporal, contudo mais metafórica: era o local de paragem dos camelos em longos percursos de viagem pelo deserto. 3. Ainda dando ao volume um aspecto de localização e paragem, al-manakh era o ponto de encontro em que nômades se reuniam para orar e trocar relatos de notícias e aventuras vividas em outras terras. No árabe moderno, al-munakh é o "clima”, não exatamente no sentido estrito das estações do ano, mas no de ambiance. A palavra é muito 
usada para nomear bairros e condomínios no mundo árabe, e como qualidade em indicações turísticas.

No entrecruzar de tais hipóteses etimológicas, temos a base para uma leitura do que seria o almanaque hoje: lugar em que baixamos de nossos cansados camelos após um ciclo solar complexo e trocamos narrativas. Apontando sobretudo para a questão de uma transmissão do saber - saber sempre em construção e expansão. Formato editorial de temas variados, de ampla circulação, de horóscopos, simpatias e orações a verbetes informativos e anedotas. $\mathrm{O}$ almanaque é um veículo de congregação de coletividades e, por isso mesmo, construtor de uma comunidade -, de geração algorítmica de bolhas e padrões de vivência e consumo. É a rede social primária.

Com diferentes experiências de munakh, sistemas de comunicação como o Facebook, o Twitter ou o Instagram configuram a versão tecnológica correspondente ao manakh de nossos dias. Cada uma dessas redes funciona como o espaço em que nos reunimos em torno de experiências individuais e informações em torno de temas e interesses cada vez mais específicos. São lugares de discurso e linguagem que propiciam a construção de diálogos, encontros, comunidades inteiras formadas por sujeitos de um infinito nomadismo que caminham sem descanso em busca de possibilidades de conhecimento e comunhão. Como afirma Byung-Chul Han, "a comunicação humana promove o sentido apenas pelo fato de que ela representa uma forma de conclusão. O ser humano se comunica para escapar à morte e para dar um sentido à vida." (HAN, 2021, p. 19). É em busca de sentido - ou na tentativa de construí-lo - que nos reunimos entre camelos cansados no deserto ou diante de nossas telas luminosas, seja compartilhando (transmitindo) ideias, imagens ou breves acenos, curtidas, likes.

Entre o almanaque tradicional e as redes digitais, há, para além da hipótese comunitária - social no sentido mais estrito do termo - , uma inegável semelhança no âmbito da forma. Por seu caráter de "texto de consulta", material por princípio fragmentado, não-li- 
near e frequentemente fruto de colaboração coletiva no que tange à autoria, almanaques e textos eletrônicos parecem obedecer a uma mesma cadeia evolutiva, em que os sites e as redes sociais oferecem ao modelo antigo novas possibilidades que potencializem seus objetivos originais. Como aponta Roger Chartier,

por um lado, a textualidade eletrônica permite desenvolver as argumentações e demonstrações segundo uma lógica que já não é necessariamente linear nem dedutiva, tal como dá a entender a inscrição de um texto sobre uma página, mas que pode ser aberta, clara e racional graças à multiplicação dos vínculos hipertextuais. Por outro, e como consequência, o leitor pode comprovar a validade de qualquer demonstração consultando pessoalmente os textos (mas também as imagens, as palavras gravadas ou composições musicais) que são o objeto da análise se, evidentemente, estiverem acessíveis numa forma digitalizada. (CHARTIER, 2002, p. 24).

Ou seja, a textualidade eletrônica proporciona a um formato que se pretendia "local de encontro" a tessitura de uma trama ainda mais rica em fios narrativos e informativos, através da expansão rizomática do discurso em uma rede de ligações e hipertextos que fazem lembrar os mapas astronômico-astrológicos dos primeiros almanaques islâmicos.

No entanto, é também na questão formal que surge uma diferença fundamental: o gesto da leitura obedece a uma fisicalidade que não conhece o virar de páginas, a manipulação do papel, quer no formato folheto, quer no formato brochura. O objeto livro é substituído pela aparente falta de materialidade da tela, em que tato e olfato são deixados de lado e a visão é exigida como nunca. O rolar infinito da tela para cima e para baixo quase que remonta ao pergaminho da antiguidade, mas sem o envolvimento do corpo, antes inteiramente necessário, agora quase inexistente na experiência da leitura. Voltando à reflexão de Chartier, 
quanto à ordem dos discursos, o mundo eletrônico provoca uma tríplice ruptura: propõe uma nova técnica de difusão da escrita, incita uma nova relação com os textos, impõe-lhes uma nova forma de inscrição. A originalidade e a importância da revolução digital apoiam-se no fato de obrigar o leitor contemporâneo a abandonar todas as heranças que o plasmaram, já que o mundo eletrônico não mais utiliza a imprensa, ignora o "livro unitário" e está alheio à materialidade do códex. (CHARTIER, 2002, p. 22).

A busca por um sentido no estarmos vivos passa pelo abandono dos sentidos do corpo e da experiência de materialidade que nos prova a existência - nossa e dos outros, que passam a nos chegar apenas como textos também transparentes e imateriais.

No âmbito do conteúdo é que surgem as maiores semelhanças entre o almanaque tradicional e as redes sociais eletrônicas. Considerando que "a revolução da textualidade digital constitui também uma mutação epistemológica que transforma as modalidades de construção e crédito dos discursos do saber" (CHARTIER, 2002, p. 25), o almanaque acaba ressurgindo como rede social avant la lettre já que desde as suas origens trabalha com a dispersão do crédito sobre o saber e com a expectativa de difusão fragmentária da informação. As divisões em recortes temáticos com foco em públicos bem definidos convergem no surgimento de grupos, páginas, hashtags, ou, para usar um termo mais genérico e que se aplique a diferentes tipos de rede, "bolhas". As bolhas são o novo manahk, em que nômades solitários se percebem parte de um grupo e se reconhecem como membros de uma comunidade com interesses e valores em comum.

Bolhas digitais podem ser o berço de movimentos culturais, de gestos políticos, ou simplesmente de exercícios de afeto. Mas é também uma tríade de possibilidades que domina o debate sobre as redes sociais do mundo digital. Os estudiosos da etnografia digital se dividem um tanto hegelianamente entre o "tecno-otimismo", o "tecno-pessimismo" e a "tecno-ambivalência” (KIDD, 2018, p. 18). 
Os tecno-otimistas apostam nas redes como esse espaço comunitário de reunião quase metafísica, de um religare da continuidade perdida. Vêem a internet como um meio de divulgação de ideias democrático e aberto ao diálogo. Acreditam que a revolução será tweetada (KIDD, 2018, p. 63). Observando a participação das redes no processo de articulação de movimentos como o Black Lives Matter, a Primavera Árabe, etc. Os tecno-pessimistas lembram do lado negativo das redes - o potencial de bullying, os ataques de ódio protegidos por um pseudo-anonimato, as fake news, a articulação de movimentos neofascistas. Argumentam ainda que o diálogo é esvaziado no meio digital, sem a capacidade de chegar às ruas ou à materialidade do encontro humano. Ecoam o desespero de Kafka: "Como se chegou à ideia de que seres humanos poderiam se relacionar uns com os outros por cartas! Pode-se pensar em uma pessoa distante e pode-se tocar uma pessoa próxima, todo o resto vai além da força humana." (KAFKA, Cartas a Milena, apud HAN, 2018, p. 95).

Fico com a dualidade da tecno-ambivalência. Entre o ser e o não-ser, o homo digitalis ainda transita nos caminhos do "vir-a-ser". Nômade em processo de formação e em busca por comunidades possíveis, o sujeito nas redes sociais é a um só tempo consumidor e produtor de informação, editor do conteúdo que lhe interessa. Assim como a produção dos almanaques foi, a princípio, uma versão mais simples que a produção tanto dos rolos quanto dos livros-códex, muitas vezes distribuído como uma espécie de panfleto ou folheto, chegando por vezes a cadernos ainda de fácil e barata confecção, o meio digital surge como possibilidade de produção e difusão de conteúdo a baixíssimo custo. Diferente das mídias modernas que emitem sua mensagem de modo unívoco, as redes permitem reação imediata e diálogo entre quem escreve e quem lê.

Curiosamente, em um texto de 1934, intitulado "O autor como produtor", Walter Benjamin ao marcar a passagem de um "autor produto" para um "autor produtor" volta as suas reflexões para um 
pensamento que constitui a construção de um projeto de comunidade em que leitores se transformam em autores. Para pensar sobre essa questão, Benjamin recorre à impressa soviética. É a partir dela que o autor vai afirmar que o jornal, por exemplo, se tornou o cenário de uma confusão literária. No jornal da imprensa soviética, “(...) a distinção entre o autor e o público, que a impressa burguesa preserva de modo convencional, começa a desaparecer" (BENJAMIN, 2012, p. 134). O conteúdo dessa imprensa é alheio a qualquer forma de organização. E essa desorganização possui uma força organizadora. Benjamin afirma que não poderíamos fechar os olhos para os novos suportes e os novos meios técnicos de produção. Não se pode partir de uma identidade pré-estabelecida, mas de forma imanente, analisar os novos meios que inserem um grande processo de transformação dos meios de transmissão.

Os jornais e, aqui, no nosso caso, as redes sociais se tornam o lugar de uma ação comum e paradoxalmente de uma ação do diferente. É nesse local onde se exerce um princípio democrático, isto é, onde qualquer leitor pode se tornar um autor. O leitor tem acesso à condição de autor. Há a queda de uma posição privilegiada diante da criação. Qualquer um pode se tornar autor. Benjamin afirma que isso diminui o distanciamento entre as esferas do autor e do leitor. Assim, a “(...) competência literária não se funda mais numa formação especializada, e sim numa formação politécnica, e com isso transforma-se em direito de todos" (BENJAMIN, 2012, p. 134). A capacidade de transmissão transforma-se em direito de todos. Assim, a construção das redes sociais convida ao estabelecimento de uma comunidade, a uma ação comum. O leitor/ autor não está afastado de sua comunidade, ele não se encontra distante, mas faz parte dela.

Entretanto, a informação produzida muitas vezes esmaga o potencial de análise e reflexão. Como escreve Byung-Chul Han, "A partir de um determinado ponto, a informação não é mais informativa 
(informativ), mas sim deformadora (deformativ), e a comunicação não é mais comunicativa, mas sim cumulativa." (HAN, 2018, p. 106).

O potencial de mero acúmulo gerado pelo excesso de informação acaba por colocar em risco exatamente o desejo comunicativo e a noção de saberes e conhecimento em um mundo hiper-informado. O nível de compreensão semiótica é comprometido pela necessidade de manter os sentidos em alerta todo o tempo. As notícias não param de chegar, os comentários não param de chegar, as imagens não param de chegar. A experiência do choque é anestesiada a cada novo clique. Ainda com Han, percebemos que Toda a história do passado como utopia, revolução e mito, flui hoje para dentro da máquina de informação como para dentro de uma barragem, que expele, então, relatos posteriores [Nachgeschichten) rapidamente consumíveis. A informação não é uma conclusão. Por isso, ela tende à proliferação e à massificação. Nisso, ela se distingue tanto do saber como também do conhecimento e da verdade. (HAN, 2021, p. 12).

O volume de informação desmidiatizada, isto é, compartilhada continuamente sem mediação de mecanismos editoriais ou órgãos de imprensa, ao mesmo tempo facilita e dificulta o acesso ao conhecimento e à comunicação em sentido estrito. Onde tudo é verdade, nada mais é; onde a informação não é digerida, o processo de reflexão não acontece. No grande almanaque sem curador - ou de curadoria compartilhada por tantos - o processo de descentralização leva luz a determinados assuntos e relega outros à escuridão e ao esquecimento, dando poder à massa, para o bem ou para o mal.

Colocando em xeque a relação entre informação e conhecimento, as redes sociais acabam por levar o almanaque a um lugar de risco. Assim como na literatura contemporânea com frequência vemos a subversão de objetos como a enciclopédia, o dicionário e o manual, sempre parodiados em sua pretensão de lugar do saber, o almanaque como formato mais popular e mais aproximado da textualidade ele- 
trônica e coletiva vai sendo também contaminado pelos riscos que envolvem as novas tecnologias discursivas. Partilhando de semelhantes qualidades e defeitos - sobretudo quanto à fé na informação e em sua importância e necessidade - talvez esteja também o velho almanaque condenado a uma certa ambivalência.

Da intenção original de ser apenas um calendário mais robusto em dados e fatos, a relação com o tempo é, provavelmente, a principal diferença entre almanaques e redes sociais. A relação com o tempo já não nos permite esperar por publicações anuais. O leitor voraz de microtextos e hiperlinks gerado pela tela luminosa nunca está satisfeito. Quando não está consumindo, está produzindo. A demanda é em mão-dupla e insaciável. Camelos sem paragens periódicas num deserto vasto e cada vez mais pobre em tempo de análise e reflexão. Vivemos no tempo dos tweets, das postagens longas que se iniciam com pedidos de desculpa por seu próprio tamanho.

Retomo novamente a etimologia:

A palavra 'digital' aponta para o dedo (dígitus) que, antes de tudo, enumera (zählt). A cultura digital se baseia no dedo contador. A história, porém, é uma narrativa (Erzählung). Ela não enumera. Enumerar é uma categoria pós-histórica. Nem tweets nem informações se reúnem em uma narrativa. Também o mural não narra nenhuma história de vida, nenhuma biografia. Ele é aditivo, e não narrativo. O homem digital passa os dedos no sentido de que ele enumera e calcula constantemente. $\mathrm{O}$ digital absolutiza o número e o enumerar. Também amigos no Facebook são, antes de tudo, contados (gezählt). A amizade, porém, é uma narrativa. A era digital totaliza o aditivo, o enumerar e o enumerável. Mesmo tendências são contadas na forma de curtidas. $\mathrm{O}$ narrativo perde enormemente em significado. Hoje tudo é formado enumerável, a fim de poder ser convertido na linguagem do desempenho e da eficiência. Assim, hoje, tudo aquilo que não é enumerável cessa de ser." (HAN, 2018, p. 66). 
Sem a vivência e a fisicalidade dos encontros, mais escassos hoje que entre os nômades do deserto islâmico, somos todos convertidos em apenas linguagem, pequenos fragmentos de textos e reações, enumerados nos murais alheios, quer em texto verbal ou em programação computadorizada, todos um bando de "uns e zeros” por onde outros grupos de seres binários passam seu dedo contador. Por outro lado, o que o tecno-pessimista Han descarta (apesar de toda a base hegeliana de sua filosofia) é mais uma vez a hipótese da ambivalência: não estamos todos nós a cada momento convertendo essas longas listas numéricas em narrativas? Será que uma espécie há tanto tempo baseada no encontro para a troca de relatos conseguiria abandonar o reflexo instintivo de imaginar contextos, biografias, diálogos e cenas inteiras? Algumas dessas micronarrativas, impulsionadas por fatos reais ou imaginários, nós até chamamos "memória" e, obediente, o Facebook nos traz de cada uma seus lembretes periódicos. Há um ano eu estive com essa pessoa, ele me lembra. Há dez anos sou amiga dessa outra, ele me avisa. E aos poucos os 0101011100 vão ilustrando narrativas que já não sei se reais ou imaginadas, vividas ou meramente programadas, se astronômicas ou astrológicas. Tudo é enumerável, mas números não são apenas outra linguagem para a nossa narrativa?

Obras de consulta e redes digitais guardam em si a promessa da velocidade. Consultar um almanaque é mais rápido que estudar a fundo sobre o tema pesquisado; correr os olhos pela timeline é mais rápido do que ler todo o noticiário ou entrar em contato com todos os conhecidos para saber de seu cotidiano. O capitalismo industrial se confunde com o capitalismo da informação, e conforme nos vemos obrigados a apertar cada vez mais parafusos por minuto, nos cobramos sempre estar a par de cada fato ocorrido em cada canto do vasto mundo, todo o tempo o tempo todo. Já existe até um diagnóstico para o mal do novo século: SFI, a Síndrome de Fadiga da Informação. Precisamos de informação rápida como de comida rápida 
(fast food), moda rápida (fast fashion), tudo para que o tempo do trabalho não seja prejudicado e a produtividade não seja afetada (nem mesmo durante uma pandemia).

Contudo, cabe observar que

o tempo que se deixa acelerar é o tempo-do-Eu (Ich-Zeit). Ele é o tempo que eu tomo para mim. Ele conduz à falta de tempo. Há, porém, também um outro tempo, a saber, o tempo do outro, um tempo que eu dou ao outro. (...) Em oposição ao tempo-do-eu, que isola e singulariza, o tempo do outro promove a comunidade." (HAN, 2021, p. 20).

O tempo dedicado à criação de narrativas diárias sobre os fragmentos de informação que nos cercam a cada instante é tempo-do-Eu na medida em que preenche minha necessidade de saber, mas também tempo-do-outro porque é o tempo em que, em busca do sentimento de comunidade e comunicação, eu abro mão do meu descanso e do meu silêncio e me lanço em direção ao outro, recebo o que o outro me oferece, ofereço minha atenção, minha palavra, meu gesto de presença na forma de um pequeno ícone que deixe o outro saber que eu o vejo, ouço, compreendo, que eu também estou aqui.

Encerro com o tecno-otimista Vilém Flusser, defensor da comunicação como gesto último de sobrevivência :

Seria o homem telemático um começo de uma antropologia que diz que ser humano é ser um telemático ser-conectado com outros, um reconhecimento recíproco que tem como fim a aventura da criatividade? (FLUSSER, Continuar a pensar a comunicalogia - as preleções de Bochum apud HAN, 2018, p. 84).

Estaríamos, apesar da fadiga de tanta informação, telemáticos ou homo digitalis, executando o projeto de comunicação almejado pelos que caminhavam solitários em busca de algo mais valioso que a 
água? Mais que uma forma contemporânea de conceber a textualidade eletrônica como herdeira semiótica do almanaque tradicional, talvez estejamos diante da materialização - ainda que tão pouco material - de um projeto que atravessou os séculos: um tipo de texto que se originou no diálogo com os astros, entre o número e o verbo, como ponte entre oriente e ocidente, registrando datas e fatos, divulgando a ciência, desde muito antes da ampulheta do tempo disparar.

RECEBIDO: $25 / 07 / 2021$ APROVADO: $18 / 08 / 2021$

\section{REFERÊNCIAS}

BARTHES, Roland. Aula: aula inaugural da cadeira de semiologia literária do Colégio de França. Tradução e posfácio de Leyla Perrone-Moisés. São Paulo: Cultrix, 2013.

BENJAMIN, Walter. Magia e técnica, arte e política: ensaios sobre literatura e história da cultura. Tradução de Sérgio Paulo Rouanet. $8^{a}$ edição. São Paulo: Brasiliense, 2012.

CHARTIER, Roger. Os desafios da escrita. Trad. Fulvia Moreto. São Paulo: Ed. Unesp, 2002.

FLUSSER, Vilém. $O$ universo das imagens técnicas: elogio da superficialidade. São Paulo: Annablume, 2008.

HAN, Byung-Chul. No enxame: perspectivas do digital. Trad. Lucas Machado. Petrópolis: Vozes, 2018.

HAN, Byung-Chul. Favor fechar os olhos: em busca de um outro tempo. Trad. Lucas Machado. Petrópolis: Vozes, 2021.

KIDD, Dustin. Social Media Freaks: Digital Identity in the Network Society. New York: Routledge, 2018.

\section{Minicurrículo}

Luciana Salles é professora de Literatura Portuguesa na Universidade Federal do Rio de Janeiro (UFRJ), onde realizou seu Mestrado em Poética e Doutorado em Literatura Portuguesa. É membro do Pólo de Pesquisas Literárias Luso-Brasileiras do Real Gabinete Português de Leitura (PLLB/ RGPL) e coordenadora do Grupo de Estudos Interdisciplinares: Linguagens, Mídia e Cultura Pop (UFRJ / CNPq). 
Marlon Augusto Barbosa possui Doutorado e Mestrado em Teoria Literária e Literatura Comparada pelo Programa de Pós-Graduação em Ciência da Literatura da Faculdade de Letras da UFRJ. Foi professor substituto de Teoria Literária e Literatura Comparada (2016 até 2017) e Literatura Portuguesa (2019 até 2021) da Faculdade de Letras da UFRJ. Atualmente é membro da Comissão Editorial e revisor da Revista Mulemba (Qualis A4). 